\title{
Fiber Textures in Copper and Iron Filaments Produced by the Glass Coated Melt Spinning*
}

\author{
By Tomoko Gotō**, Hazime Murakami***, Keizō Tanaka*** \\ and Masamitsu Nagano****
}

\begin{abstract}
Fiber textures in copper and iron filaments produced by the glass coated melt spinning under various conditions are investigated by the X-ray diffraction method. A single [100] fiber texture is observed for copper filaments and a single [111] texture for iron.

The distribution of crystallite orientation is evaluated by the orientation function $f=$ $1 / 2\left(3\left\langle\cos ^{2} \varphi_{j}\right\rangle-1\right)$, where $\varphi_{j}$ denotes the angles between the fiber axis and crystallographic principal axes, and $\left\langle\cos ^{2} \varphi_{j}\right\rangle$ represents the mean square of directional cosines $\varphi_{j}$. The orientation functions of copper and iron filaments are evaluated from the diffraction intensity distribution along the Debye rings for $\{200\}$ and $\{110\}$ planes. It is found that the degree of sharpness in fiber texture increases with winding speed in the spinning process.
\end{abstract}

(Received June 26, 1976)

\section{Introduction}

In anisotropic polycrystalline materials, such as fibers, polymeric films and rolled metals, the distribution of crystallite orientation is of practical importance, and it is known that various types of fiber texture are formed in the case of cold drawing or swaging of metal wires $^{(1)}$.

The authors have studied the glass coated melt spinning of metal by Ulitovskiy's method $^{(2)}$. In this method the metallic filaments are formed in a short time by solidification followed by drawing process. The deformation texture of such a filament is of interest for practical purposes. This paper describes fiber textures in copper and iron filaments spun in various spinning conditions.

* This paper was originally published in Japanese, in J. Soc. Fiber Science and Technology, Japan, 32 (1976), T-61.

** Department of Fiber and Polymer Technology, Nagaya Institute of Technology, Gokiso-chō, Shōwa-ku, Nagoya 466, Japan.

*** Graduate School, Nagoya Institute of Technology, Gokiso-chō, Shōwa-ku, Nagoya 466, Japan.

**** Nagoya Institute of Technology, Nagoya, Present address: College of Tokyo Kasei, Itabashi-ku, Tokyo 173, Japan.

\section{Experimental}

Copper and iron filaments were produced by the method of glass coated melt spinning as described before ${ }^{(2)}$. About $1 \mathrm{~g}$ of metal was melted in a glass tube using an induction heating coil. The molten metal was kept globular and suspended in a fixed position. Then the molten metal was drawn, with the glass, from the bottom of the globule and the solid metal coated by glass was coiled up to a winding drum. A continuous melt spinning of copper (99.9\% purity) for a long time was made possible by making use of spinnability of pyrex glass. Vycor glass was used for commercial pure iron $(99.98 \%$ purity containing $0.003 \% \mathrm{C}, \quad 0.004 \% \mathrm{P}, \quad 0.005 \% \mathrm{Si}, \quad 0.005 \% \mathrm{Cu}$ ). Due to the poor spinnability of vycor glass, the continuous iron filament coiled up to only a few hundred meters was obtained. The spinning conditions for them are shown in Table 1. The coated glass was removed by dissolving it into fused $\mathrm{NaOH}$ for $10 \mathrm{sec}$ and then the filament was rinsed in aqueous methanol.

Microscopic observation of the filaments produced in this way was made by a scanning electron microscope.

The X-ray diffraction method was used to investigate the fiber textures of the filaments. A flat cassette camera was used to take X-ray

1977 Vol. 18 
Table 1 The spinning conditions of glass coated melt spinning of metal.

\begin{tabular}{|c|c|c|c|c|c|c|c|c|c|c|}
\hline \multirow{2}{*}{ Number } & \multirow{2}{*}{ Metal } & \multirow{2}{*}{$\begin{array}{l}\text { Melting } \\
\text { Temp. } \\
\left({ }^{\circ} \mathrm{C}\right)\end{array}$} & \multirow{2}{*}{$\begin{array}{c}Z_{T}^{*} \\
(\mathrm{~cm})\end{array}$} & \multirow{2}{*}{$\begin{array}{l}\text { Winding } \\
\text { speed } \\
(\mathrm{m} / \mathrm{min})\end{array}$} & \multirow{2}{*}{$\begin{array}{l}\text { Winding } \\
\text { tension } \\
\left(\mathrm{kg} / \mathrm{mm}^{2}\right)\end{array}$} & \multicolumn{2}{|c|}{ Cross-sectional area } & \multirow{2}{*}{$\begin{array}{l}\text { Percent } \\
\text { reduction } \\
\text { in area }\end{array}$} & \multirow{2}{*}{$\begin{array}{l}\text { Diameter of } \\
\text { filament } \\
(\mu)\end{array}$} & \multirow{2}{*}{$K^{* *}$} \\
\hline & & & & & & $A_{\mathrm{o}}\left(\mathrm{cm}^{2}\right)$ & $A_{w}\left(\mathrm{~cm}^{2}\right)$ & & & \\
\hline 1 & Copper & 1300 & 8 & 90 & 2.2 & $1.0 \times 10^{-4}$ & $3.8 \times 10^{-7}$ & 99.62 & $7 \pm 1$ & 0.3039 \\
\hline 2 & Copper & 1300 & 8 & 238 & 7 & $6.6 \times 10^{-5}$ & $4.9 \times 10^{-8}$ & 99.92 & $2.5 \pm 1$ & 0.0903 \\
\hline 3 & Copper & 1300 & 10 & 477 & 6.5 & $3.2 \times 10^{-5}$ & $4.5 \times 10^{-8}$ & 99.86 & $2 \pm 1$ & 0.0401 \\
\hline 4 & Iron & 2000 & 60 & 61 & - & $3.1 \times 10^{-3}$ & $1.3 \times 10^{-5}$ & 99.58 & $40 \pm 10$ & 17.7 \\
\hline 5 & Iron & 2000 & 40 & 477 & - & $3.3 \times 10^{-4}$ & $5.0 \times 10^{-7}$ & 99.85 & $8 \pm 3$ & 0.328 \\
\hline
\end{tabular}

$Z_{T}^{*}$ : Distance from the bottom of the globule where the temperature of the filament dropped to room temperature.

$K^{* *}$ : The weight ratio of metallic filament to coated glass.

$A_{0}, A_{w}$ : Cross-sectional areas at the bottom of the globule and at the winding drum, respectively.

diffraction patterns. The distribution of crystallite orientation about the fiber axis was evaluated by the orientation function, generally used in the study of the crystalline polymers $^{(3) \sim(5)}$. The coordinate system shown in Fig. 1 was taken to describe the orientation function in the filament with a single $[h, k, l]$ fiber texture. The angle $\phi_{j}(j=\mathrm{a}, \mathrm{b}, \mathrm{c})$ indicates the angles between Z-axis (fiber axis) and the crystallographic principal axes ( $a, b$ and $c)$. Orientation function

$f_{h k l}$ is defined as $f_{h k l}=\left(3\left\langle\cos ^{2} \phi_{j=\mathrm{c}}\right\rangle-1\right) / 2$,

where $\left\langle\cos ^{2} \phi_{j}\right\rangle$ is given by

$$
\begin{array}{r}
\left\langle\cos ^{2} \phi_{j}\right\rangle=\int_{0}^{\pi / 2} I_{\phi_{j}} \cos ^{2} \phi_{j} \sin \phi_{j} d \phi_{j} \\
/ \int_{0}^{\pi / 2} I_{\phi_{j}} \sin \phi_{j} d \phi_{j} .
\end{array}
$$

Here, $I_{\phi_{j}}$ is the diffraction intensity at an angle $\phi_{j}$ of the crystallographic plane perpendicular to the $j$-axis. For the case of cylindrical symmetry about the fiber axis, $f_{h k l}$ can be represented by

$$
f_{h k l}=1-3\left\langle\cos ^{2} \phi_{j=\mathrm{a}}\right\rangle=1-3\left\langle\cos ^{2} \phi_{j=\mathrm{b}}\right\rangle .
$$

The diffraction intensity distribution along the Debye ring was measured by an X-ray diffractometer with a special goniometer for fiber specimens.

\section{Results}

The copper filament produced is shown in Photo. 1. The filament has a smooth surface

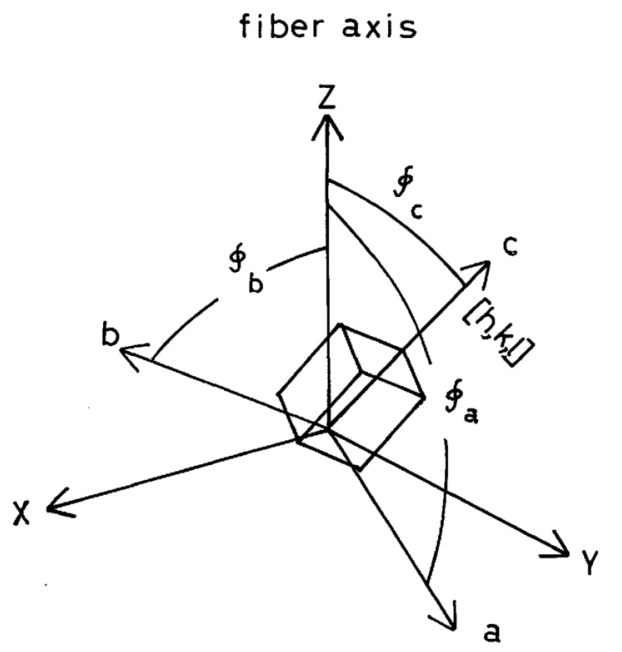

Fig. 1 The coordinate system taken for describing the uniaxial orientation in the filament with a single $[h k l]$ fiber texture.

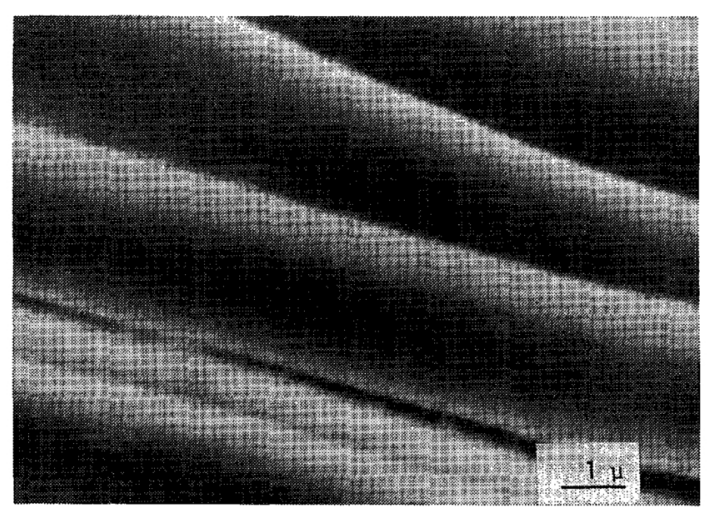

Photo. 1 The surface structure of copper filament spun at a winding speed of $477 \mathrm{~m} / \mathrm{min}$. 
and is free from pinholes. The deformation bands nearly parallel to the fiber axis can be observed. A similar surface structure was also observed for the iron filament.

The fiber texture of the filament was examined by the X-ray diffraction method. Photograph 2 shows a typical X-ray diffraction pattern for copper filaments. The inner and outer rings are from $\{111\}$ and $\{200\}$ planes, respectively, and the intensity maxima of these rings show that a single [100] fiber texture was formed in the copper filament. The data for determination of the fiber axis using the $\mathrm{X}$-ray diffraction pattern of the iron filament are shown in Table 2. A single [111] fiber texture was deduced for iron. The distribution of crystallite orientation about the fiber axis was described by the orientation function. Figure 2 shows typical diffraction intensity distribution curves along the $\{200\}$ ring for the copper filament, plotted $I_{\phi}$ vs $\phi, I_{\phi} \sin \phi$ vs $\phi$ and $I_{\phi} \cos ^{2} \phi \sin \phi$ against $\phi$. If the $\mathrm{c}$ axis in Fig. 1 coincides with the [100] direction, range 1 of Fig. 2 arises from the disribution for the (100) plane and range 2 is due to those of the (010) and (001) planes. Using the intensity distribution curve for the (100) plane, the integrations $\int_{0}^{\pi / 2} I_{\phi} \cos ^{2} \phi$ $\sin \phi d \phi$ and $\int_{0}^{\pi / 2} I_{\phi} \sin \phi d \phi$ were carried out graphically and the values of $\left\langle\cos ^{2} \phi_{100}\right\rangle$

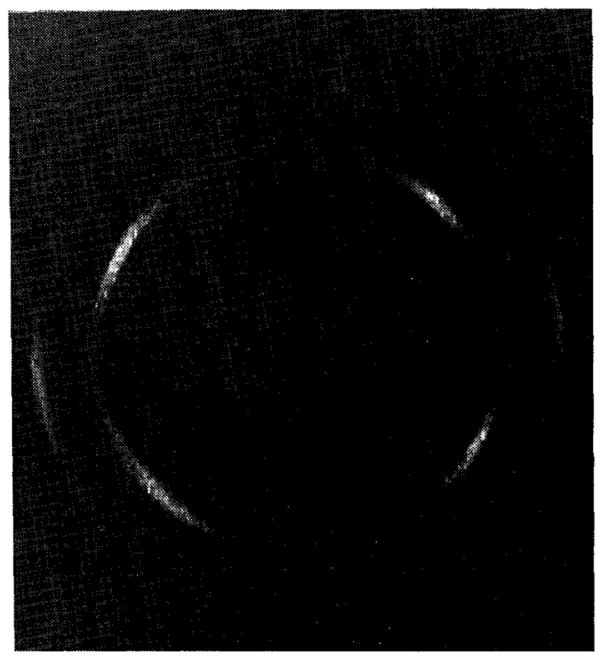

Photo. 2 X-ray diffraction pattern of copper filament, taken by a flat cassette camera, the distance from the sample to the film being $3.0 \mathrm{~cm}$. Nickelfiltered $\mathrm{Cu}-\mathrm{K} \alpha$ radiation were used.

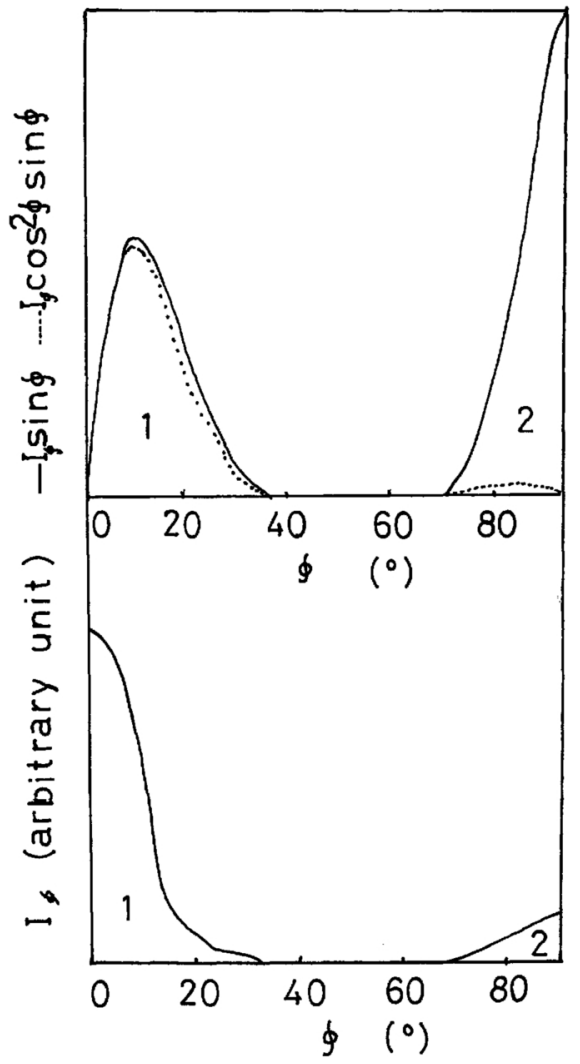

Fig. 2 The diffraction intensity distribution curves along the $\{200\}$ ring for the copper filament spun at a winding speed of $136 \mathrm{~m} / \mathrm{min}$. Plotted $I_{\phi}$, $I_{\phi} \sin \phi$ and $I_{\phi} \cos ^{2} \phi \sin \phi$ against $\phi$. Range 1 is due to the (100) plane and range 2 is $(010)$ and (001).

and $f_{100}$ were evaluated from eqs. (2) and (1), respectively. For example, in the case of Fig. 2 they were found to be $\left\langle\cos ^{2} \phi_{100}\right\rangle=0.931$ and $f_{100}=0.897$.

In order to appraise the orientation function of the iron filament having a single [111] fiber texture, an assumption that the axes $a, b$ and c coincide with [1 $1 \overline{1} 0],[\overline{2} 11]$ and [111] directions, respectively, was introduced for convenience. The typical intensity distribution for $\{110\}$ reflection plane for the iron filament is shown in Fig. 3. The peak belonged to range 1 corresponds to the distribution for the (1T0) plane and range 2 is due to the (110) plane. From the analyses of the intensity distribution curves for the $(1 \overline{1} 0)$ reflection plane in the same way as mentioned above, $\left\langle\cos ^{2} \phi_{1 \overline{1} 0}\right\rangle$ and $f_{111}$ were evaluated from eqs. (2) and (3), re- 
Table 2 The determination of fiber axis of iron filament from X-ray diffraction pattern.

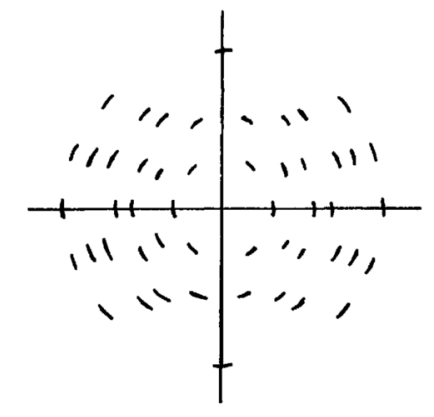

A schematic X-ray pattern, the distance from the sample to the film being $35 \mathrm{~mm}$. Ag radiation was used.

\begin{tabular}{|c|c|c|c|c|c|c|}
\hline Number & $\begin{array}{l}\text { Plane } \\
(h k l)\end{array}$ & $\begin{array}{c}2 \theta \\
\operatorname{Ag}\left({ }^{\circ}\right)\end{array}$ & $\stackrel{\alpha}{\left({ }^{\circ}\right)}$ & $\begin{array}{c}\rho^{*} \text { ob. } \\
\left({ }^{\circ}\right)\end{array}$ & $\begin{array}{c}\text { Fiber axis } \\
{[u v w]}\end{array}$ & $\begin{array}{c}\rho \text { cal. } \\
\left({ }^{\circ}\right)\end{array}$ \\
\hline \multirow[t]{2}{*}{1} & 110 & 15.9 & 34.3 & 35.1 & 111 & 35.3 \\
\hline & & & 90.0 & 90.0 & 111 & 90.0 \\
\hline 2 & 200 & 22.5 & 59.7 & 60.3 & 111 & 54.7 \\
\hline \multirow[t]{3}{*}{3} & 211 & 27.7 & 15.0 & 20.3 & 111 & 19.5 \\
\hline & & & 61.5 & 62.4 & 111 & 61.9 \\
\hline & & & 90.0 & 90.0 & 111 & 90.0 \\
\hline \multirow[t]{2}{*}{4} & 220 & 32.0 & 34.3 & 35.1 & 111 & 35.3 \\
\hline & & & 90.0 & 90.0 & 111 & 90.0 \\
\hline \multirow[t]{2}{*}{5} & 310 & 35.9 & 40.0 & 43.2 & 111 & 43.1 \\
\hline & & & 67.5 & 68.7 & 111 & 68.6 \\
\hline 6 & 222 & 39.5 & 69.0 & 70.3 & 111 & 70.5 \\
\hline \multirow[t]{4}{*}{7} & 321 & 42.8 & 0.0 & 21.4 & 111 & 22.2 \\
\hline & & & 49.0 & 52.4 & 111 & 51.9 \\
\hline & & & 69.0 & 70.5 & 111 & 72.0 \\
\hline & & & 90.0 & 90.0 & 111 & 90.0 \\
\hline
\end{tabular}

* From the equation of $\cos \alpha \times \cos \theta=\cos \rho$. Here $\alpha$ is the angle between the standard line, which is through the center of film and parallel to the fiber axis, and the position of diffraction intensity maxima of the Debye rings. $\theta$ is the Bragg angle and $\rho$ is the angle between the diffraction plane normal and the fiber axis.

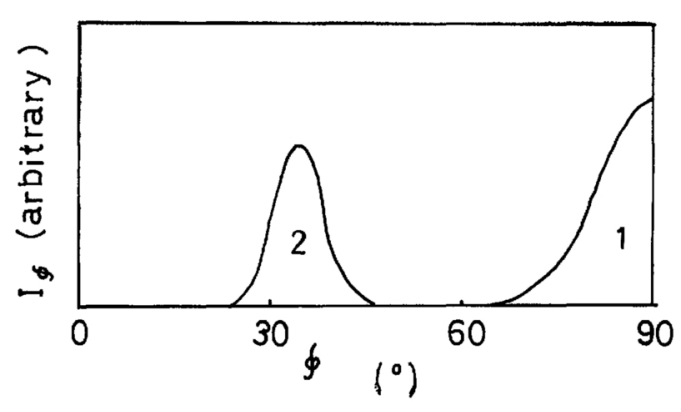

Fig. 3 The diffraction intensity distribution curves along the $\{111\}$ ring for the iron filament spun at a winding speed of $147 \mathrm{~m} / \mathrm{min}$. Range 1 is due to the (110) plane and range 2 is (110).

spectively.

The orientation functions of copper and iron filaments spun at various winding speeds were determined. The variation of the orientation function with the winding speed is shown in Fig. 4, and the results show that the orientation function increases as the winding speed increases.

\section{Discussion}

The surface of the filament obtained in the present study was smooth due to the constraint by the coated glass. Frequently, the deformation bands nearly parallel to the fiber axis were observed.

A single [100] fiber texture was observed for copper filaments and a single [111] fiber texture for iron. The degree of sharpness in fiber texture increased with increasing winding speed in the spinning process. It is well known that the double [111] $+[100]$ textures are formed in 


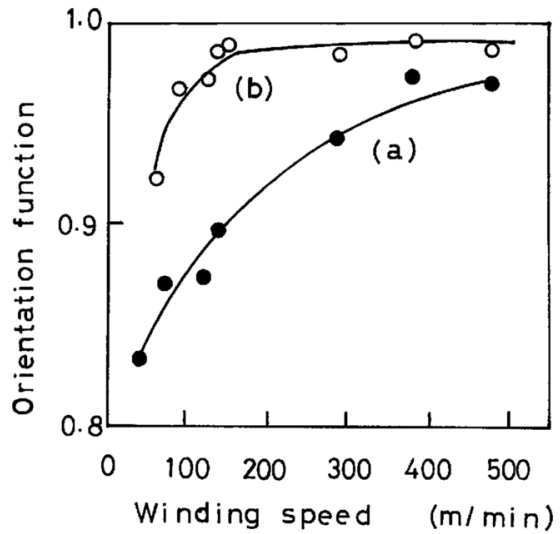

Fig. 4 The orientation functions of metallic filaments spun at various winding speeds. (a) copper filament, (b) iron filament.

$f c c$ metal and the single [110] texture in bcc metal by cold drawing, and a single [100] texture is often produced in cubic metal during the solidification process $^{(1)}$. In the melt spinning process of metals, it seems that two types of texture formation due to drawing and solidification process may take place and contribute to the final texture. Moreover, the solid phase transformations appear to affect the formation of the texture in the iron filament. It has been reported that the $\mathbf{A}_{3}$ transformation temperature of iron containing less than $0.003 \% \mathrm{C}$ falls gradually with increase in cooling rate and continuously approaches a fixed temperature $\left(650^{\circ} \mathrm{C} \text { for } 0.003 \% \mathrm{C}\right)^{(6)}$ and the transformation is suggested to occur martensitically ${ }^{(6) \sim(8)}$. The cooling rate of the iron filament at $650^{\circ} \mathrm{C}$ is considered to be about $10^{4}-10^{5} \mathrm{C} / \mathrm{sec}$ due to the small diameter of the filament and high heat transfer coefficient at the surface of coated glass ${ }^{(9)}$, and the martensitic transformation may occur at about $650^{\circ} \mathrm{C}$. As it is known that the habit plane of iron containing less than $0.4 \% \mathrm{C}$ is $\{111\}$ for the $f c c$ structure and the orientation relation follows the Kurdjumov-Sachs relation $^{(10)(11)}$, it appears that the fiber texture upon the solid phase transformations follows this K-S relation.

\section{Conclusion}

The copper and iron filaments were produced by the glass coated melt spinning. The surface of the filament was smooth and the deformation bands were frequently observed. Fiber textures in the filaments were investigated by the X-ray diffraction method. A single [100] fiber texture was observed for copper filaments and a single [111] fiber texture for iron. The degree of sharpness in fiber texture increased with increasing winding speed in the spinning process.

\section{REFERENCES}

(1) G. Wassermann und J. Grewen: Texturen metallischer Werkstoffe, Springer-Verlag, Berlin, (1962).

(2) T. Gotō: Bull. Japan Inst. Metals, 15 (1976), 633.

(3) R. S. Stein: J. Poly. Sci., 31 (1958), 327.

(4) J. Roe and W. R. Krigbaum: J. Chem. Phys., 40 (1964), 2608; 41 (1964), 737.

(5) L. E. Alexander: $X$-ray diffraction methods in polymer science, John Wiley \& Sons, Inc., New York, (1969).

(6) M. Izumiyama, M. Tsuchiya and Y. Imai: J. Japan Inst. Metals, 34 (1970), 286.

(7) M. J. Bibby and J. G. Parr: J. Iron Steel Inst., 202 (1964), 100.

(8) E. Eichen and J. W. Spretnak: Trans. ASM, 51 (1959), 454.

(9) P. Duwez: Trans. ASM, 60 (1967), 607.

(10) Japan Inst. Metals: Metal Handbook, Maruzen, Tokyo, (1972), 199.

(11) G. Kurdjumov and G. Sachs: Z. Phys., 84 (1930), 325. 